\title{
DATA ENVELOPMENT ANALYSIS OF BANKING SECTOR IN BANGLADESH
}

\author{
Md. Rashedul Hoque, Researcher \\ Dr. Md. Israt Rayhan, Assistant Professor \\ Institute of Statistical Research and Training, University of Dhaka, Dhaka-1000, Bangladesh \\ Phone: (++880) 1670809167, 1924752885, E-mail: rhoque@isrt.ac.bd, israt@isrt.ac.bd
}

Received May 12, 2012

\begin{abstract}
Banking sector of Bangladesh is flourishing and contributing to its economy. In this aspect measuring efficiency is important. Data Envelopment Analysis technique is used for this purpose. The data are collected from the annual reports of twenty four different banks in Bangladesh. Data Envelopment Analysis is mainly of two types - constant returns to scale and variable returns to scale. Since this study attempts to maximize output, so the output oriented Data Envelopment Analysis is used. The most efficient bank is one that obtains the highest efficiency score.
\end{abstract}

\section{KEY WORDS}

Operations research; Farm inputs; Statistics; Assets; Methods; Sampling; Costs; Performance.

Financial institutions around the world experienced substantial changes in the last few years. Technological progress, reduced information costs, fiercer competition among both bank and non-bank financial intermediaries and ongoing deregulation all led to substantial changes in numerous financial systems. Bank efficiency has been an important issue in this transition. There are two types of methods to measure comparative efficiency: parametric and non-parametric methods. The non-parametric approaches use mathematical programming techniques (Coelli, 1996); among those Data Envelopment Analysis (DEA) is widely used. The primary focus of DEA is to measure the production or performance function of DMUs (decision making unit).

DEA evaluates the inputs consumed and outputs produced by DMUs and identify those units that comprise an efficient frontier and those that lie below this frontier. The standard DEA models have an input and output orientation. An input orientation identifies the efficient consumption of resources while holding outputs constant. An output orientation identifies the efficient level of output given existing resource consumption. The output orientation provides estimates of the amount by which outputs could be proportionally expanded given existing input levels. In addition, DEA models can be either constant or variable returns to scale (Banker et al., 1984). DEA model can be used with very small data precisely because it is a non-parametric approach.

Efficiency of firm is measured in terms of its relative performance that is, efficiency of a firm relative to the efficiencies of firms in a sample. Data Envelopment Analysis (DEA) has used to identify banks that are on the output frontier given the various inputs at their disposal. Jackson and Fethi (2000) study on Turkish banks found that the profitable banks are more likely to operate at higher levels of technical efficiency. Seiford and Thrall (1990) found that mathematical programming procedure used by DEA for efficient frontier estimation is comparatively robust. DEA is a linear programming model introduced by Charnes et al. (1978) to measure efficiency under the assumption of constant returns to scale and extended by Banker et al. (1984) to allow variable returns to scale. A large number of papers have extended and applied the DEA methodology (Coelli, 1996).

Bhattacharyya et al. (1997) examined the productive efficiency of 70 Indian commercial banks during early stages (1986-1991) prior to liberalization. They used DEA to calculate radial technical efficiency scores. Sathye (2003) measured the productive efficiency of banks in India using DEA. The study shows that the mean efficiency score of Indian banks compares well with the world mean efficiency score. Sufian (2007) has employed the DEA method to investigate the 
effects of mergers and acquisitions on the efficiency of Malaysian banks. DEA has become increasingly popular in measuring efficiency in different national banking institutes. Dwivedi and Charyulu (2011) seek to determine the impact of various market and regulatory initiatives on efficiency improvements of Indian banks.

\section{DATA AND METHODOLOGY}

The data for this study are collected from 24 banks through the annual reports of the year 2010. Some of the annual reports are obtained from respective bank's websites and some others are collected from the respective bank's headquarters. This study mainly emphasis on five variables, these are: operation profit, operation income, operation cost, total assets and deposits. For the purpose of efficiency analysis operation profit is considered as output variable that is to be maximized and the other four variables are considered as input variables.

A linear program is applied to create a virtually efficient DMU that sits on the efficiency frontier, in which each DMU has a hundred (100) percent efficiency relative to every other DMU. The linear program uses two constraints. The first constraint forces the virtual DMU to produce at least as many outputs as the studied DMU. The second constraint finds out how much input the virtual DMU would need.

Let us begin with input oriented constant returns to scale (CRS) model. Let us consider there are data on $\mathrm{K}$ inputs and $\mathrm{M}$ outputs on each of $\mathrm{N}$ DMU's. For the i-th DMU these are represented by the vectors $x_{i}$ and $y_{i}$, respectively. The $K \times N$ input matrix $\mathrm{X}$, and the $\mathrm{M} \times \mathrm{N}$ output matrix $\mathrm{Y}$, represent the data of all DMU's. For each DMU we would like to obtain a measure of the ratio of all outputs over all inputs such as $u^{\prime} y_{i} / v^{\prime} x_{i}$ as efficiency score, where $\mathrm{u}$ is an $\mathrm{M}^{\mathrm{X}_{1}} 1$ vector of output weights and $\mathrm{v}$ is a $\mathrm{K}^{\mathrm{X}_{1}} 1$ vector of input weights.

Now for selecting optimal weights we write the mathematical programming problem as follows:

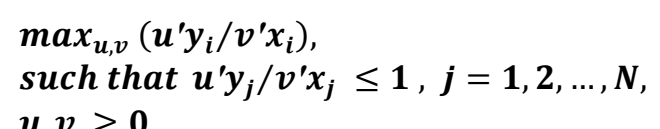

This involves finding values for $\mathrm{u}$ and $\mathrm{v}$ such that the efficiency measure of the i-th DMU is maximized, subject to the constraint that all efficiency measures must be less than or equal to one. A great problem with this particular ratio formulation is that it has an infinite number of solutions. To avoid this we can impose the restriction $v^{\prime} x_{i}=1$, which gives:

$$
\begin{aligned}
& \max _{\mu, v}\left(\mu^{\prime} y_{i}\right), \\
& \text { such that } v^{\prime} x_{i}=1, \\
& \mu^{\prime} y_{j}-v^{\prime} x_{j} \leq 0, j=1,2, \ldots, N, \\
& \mu, v \geq 0
\end{aligned}
$$

where the notation change from $\mathrm{v}$ to $\mu$ and $\mathrm{v}$ is reflecting the transformation here. This form is called the multiplier form of the linear programming problem. Using the duality in linear programming; one can derive an equivalent envelopment form of this problem:

$$
\begin{aligned}
& \min _{\theta, \lambda} \theta, \\
& \operatorname{such}_{\text {that }}-y_{i}+Y \lambda \geq 0, \\
& \theta x_{i}-X \lambda \geq 0, \\
& \lambda \geq 0,
\end{aligned}
$$

where $\theta$ is a scalar and $\lambda$ is a $\mathrm{N} \times 1$ vector of constants. This envelopment form involves fewer constraints than the multiplier form $(\mathrm{K}+\mathrm{M}<$ $\mathrm{N}+1$ ), and hence is generally the preferred form to solve. The value of $\theta$ obtained will be the efficiency score for the $\mathrm{i}$-th DMU. The value of $\theta$ obtained will be the efficiency score for the i-th DMU. It will satisfy $\theta \leq 1$, with a value of 1 indicating a point on the frontier and thus a technically efficient DMU is obtained according to the Farrell (1957) definition.

The CRS linear programming problem can be easily modified to account for variable returns to scale (VRS) by adding the convexity constraint: $N 1^{\prime} \lambda=1$ to (3) to provide:

$$
\begin{array}{ll}
\min _{\theta, \lambda} \theta, & \\
\operatorname{such}_{\text {that }}- & y_{i}+Y \lambda \geq 0, \\
& \theta x_{i}-X \lambda \geq 0, \\
& N 1^{\prime} \lambda=1 \\
& \lambda \geq 0,
\end{array}
$$

where N1 is an $N \times 1$ vector of ones. This procedure provides TE (technical efficiency) scores which are greater than or equal to those obtained using the CRS model. 
Scale efficiency is calculated as follows: Scale Efficiency $=($ TE obtained from CRS/TE obtained from VRS $)$

One limitation of this measure of scale efficiency is that the value does not indicate whether the DMU is operating in the area of increasing or the decreasing returns to scale. This may be determined by running an addition DEA problem with non- increasing returns to scale (NIRS) imposed. This can be done by altering the DEA model in equation 4 by substituting the $N 1^{\prime} \lambda=1$ restriction with $N 1^{\prime} \lambda \leq 1$, to provide:

$$
\begin{array}{ll}
\min _{\theta, \lambda} \theta, & \\
\operatorname{such} \text { that }- & y_{i}+Y \lambda \geq 0 \\
& \theta x_{i}-X \lambda \geq 0 \\
& N 1 ' \lambda \leq 1 \\
\lambda \geq 0
\end{array}
$$

The nature or characteristics of the scale inefficiencies (due to increasing or decreasing returns to scale) for a particular DMU can be determined by seeing whether the NIRS TE score is equal to the VRS TE score. The output-oriented models are very similar to their input-oriented counterparts. Let us assume the example of the following output-oriented VRS model:

$$
\begin{gathered}
\max _{\emptyset, \lambda} \phi, \\
s t \quad-\phi y_{i}+Y \lambda \geq 0, \\
x_{i}-Y \lambda \geq 0, \\
N 1^{\prime} \lambda=1 \\
\lambda \geq 0,
\end{gathered}
$$

where $1 \leq \emptyset<\infty$, and $\emptyset-1$ is the proportional increase in outputs that could be achieved by the i-th DMU, with input quantities held constant. Note that, $1 / \varnothing$ defines a TE score which ranges between zero and one. One point that should be noted is that the output- and input- oriented models will estimate the same frontier and therefore, identify the same set of DMU's as being efficient.

\section{RESULTS AND INTERPRETATIONS}

The following table shows the descriptive statistics of the sample $n=24$ banks.

Table 1 - Descriptive Statistics of the Banks*

\begin{tabular}{|c|c|c|c|c|c|}
\hline Variables & Mean & Median & Minimum & Maximum & $\begin{array}{c}\text { Standard } \\
\text { deviation }\end{array}$ \\
\hline Operation profit & 5030.10 & 4164.50 & 994.50 & 12080.80 & 2987.90 \\
\hline Operation income & 8201.00 & 6880.00 & 2633.00 & 18742.00 & 4545.00 \\
\hline Operation cost & 3172.00 & 2635.00 & 1280.40 & 7862.00 & 1893.90 \\
\hline Assets & 123860.00 & 98050.00 & 55170.00 & 345710.00 & 79604.50 \\
\hline Deposits & 99680.00 & 78670.00 & 44850.00 & 291930.00 & 67749.90 \\
\hline
\end{tabular}

*The above table is figured in units of million BDT taka (currency of Bangladesh with 1 USD $=81.8$ BDT)

Under the CRS assumption both the output and input oriented technical efficiency scores are same. Here, all the efficiency scores of DEA are obtained using the DEAP- xp1 software developed by Tim Coelli (1996). All the CRS (output), VRS (output) and scale efficiency scores of the banks along with the peers are given in the table 2 .

Table 2 shows the technical efficiency scores for all the DMUs. Here we see that under the CRS output results only three banks- SOUTHEAST BANK LIMITED (DMU 12), NATIONAL BANK LIMITED (DMU 19) and AB BANK LIMITED (DMU 22) are technically efficient because they have the technical efficiency scores equal to one. We note that the technical efficiency (TE) of DMU 1 is 0.879 . That is DMU 1 should be able to increase the operating profit by $12.1 \%$ without increasing inputs. Similar interpretation holds for the other DMUs. A remarkable thing is that DMU 12 is recognized as most efficient bank because the linear combination of DMU 12 is more used than DMU 19 or DMU 22 as peer. So, using CRS output oriented multi stage DEA, the DMU 12 is most efficient though all of DMUs 12, 19 and 22 have technical efficiency score equal to one.

Under the VRS output results the 12 banksEXIM BANK (DMU 7), MUTUAL TRUST BANK LMITED (DMU 9), ONE BANK LIMITED (DMU 10), TRUST BANK LIMITED (DMU 11), SOUTHEAST BANK LIMITED (DMU 12), JAMUNA BANK LIMITED (DMU 14), SOCIAL ISLAMI BANK LIMITED (DMU 17), EASTERN BANK LIMITED (DMU 18), 
NATIONAL BANK LIMITED (DMU 19), JANATA BANK LIMITED (DMU 20), AB BANK LIMITED (DMU 22), and AGRANI BANK LIMITED (DMU 23) are technical efficient. Other 12 banks are technically inefficient as their efficiency scores are less than one. Technical efficient DMUs are peer of themselves only. We know that only the efficient DMUs form the linear combinations for the inefficient DMUs for effi- ciency perspective. For example, DMU 15 is a linear combination of the DMUs 10, 18 and 19. That is, this linear combination of and 10, 18 and 19 determines the efficient output of DMU 15. The peer counts for DMU 12 is 9 whereas for DMU 10 it is 6 and for the other efficient DMUs 7, 18, 19, 20 and 22 the peer counts are 4, 4, 6, 2 and 1 are respectively. Since DMU 12 is most used, so the most efficient bank is DMU 12.

Table 2 - Efficiency Scores obtained using DEA*

\begin{tabular}{|c|c|c|c|c|c|c|}
\hline DMUs & $\begin{array}{c}\text { CRS } \\
\text { TE }\end{array}$ & CRS Peers & $\begin{array}{l}\text { VRS } \\
\text { TE }\end{array}$ & VRS Peers & $\begin{array}{c}\text { SCALE } \\
\text { TE }\end{array}$ & - \\
\hline 1 & 0.879 & $22(0.041), 12(0.596)$ & 0.952 & $12(0.270), 7(0.038), 10(0.693)$ & 0.924 & irs \\
\hline 2 & 0.829 & $12(0.180), 19(0.430)$ & 0.873 & $10(0.699), 19(0.301)$ & 0.949 & irs \\
\hline 3 & 0.785 & $22(0.449), 12(0.232)$ & 0.805 & $\begin{array}{l}19(0.148), 10(0.190), 12(0.106), \\
18(0.555)\end{array}$ & 0.975 & irs \\
\hline 4 & 0.606 & $19(0.783)$ & 0.638 & $10(0.386), 19(0.614)$ & 0.951 & irs \\
\hline 5 & 0.759 & $\begin{array}{l}19(0.228), 22(0.507) \\
12(0.156)\end{array}$ & 0.762 & $\begin{array}{l}19(0.362), 22(0.222), 12(0.131), \\
18(0.285)\end{array}$ & 0.996 & irs \\
\hline 6 & 0.844 & $\begin{array}{l}19(0.119), 22(0.067) \\
12(0.990)\end{array}$ & 0.889 & 12(0.631), 20(0.105),19(0.264) & 0.949 & irs \\
\hline 7 & 0.891 & $12(0.519)$ & 1.000 & $7(1.000)$ & 0.891 & irs \\
\hline 8 & 0.691 & $19(0.125), 12(0.491)$ & 0.731 & $10(0.597), 12(0.252), 18(0.151)$ & 0.944 & irs \\
\hline 9 & 0.740 & $12(0.400)$ & 1.000 & $9(1.000)$ & 0.740 & irs \\
\hline 10 & 0.907 & $12(0.289), 19(0.154)$ & 1.000 & $10(1.000)$ & 0.907 & irs \\
\hline 11 & 0.786 & $12(0.428)$ & 1.000 & $11(1.000)$ & 0.786 & irs \\
\hline 12 & 1.000 & $12(1.000)$ & 1.000 & $12(1.000)$ & 1.000 & - \\
\hline 13 & 0.749 & $12(0.561)$ & 0.844 & $12(0.082), 7(0.412), 10(0.506)$ & 0.887 & irs \\
\hline 14 & 0.809 & $12(0.440)$ & 1.000 & $14(1.000)$ & 0.809 & irs \\
\hline 15 & 0.859 & $12(0.122), 19(0.407)$ & 0.994 & $10(0.638), 18(0.294), 19(0.068)$ & 0.864 & irs \\
\hline 16 & 0.768 & $12(1.840)$ & 0.913 & $12(0.301), 20(0.699)$ & 0.841 & drs \\
\hline 17 & 0.475 & $12(0.310)$ & 1.000 & $17(1.000)$ & 0.475 & irs \\
\hline 18 & 0.980 & $22(0.479), 12(0.099)$ & 1.000 & $18(1.000)$ & 0.980 & irs \\
\hline 19 & 1.000 & $19(1.000)$ & 1.000 & $19(1.000)$ & 1.000 & - \\
\hline 20 & 0.810 & $12(2.203)$ & 1.000 & $20(1.000)$ & 0.810 & $\mathrm{drs}$ \\
\hline 21 & 0.642 & $12(0.563)$ & 0.710 & $12(0.091), 7(0.794), 10(0.115)$ & 0.904 & irs \\
\hline 22 & 1.000 & $22(1.000)$ & 1.000 & $22(1.000)$ & 1.000 & - \\
\hline 23 & 0.816 & $22(0.126), 12(1.812)$ & 1.000 & $23(1.000)$ & 0.816 & drs \\
\hline 24 & 0.757 & $12(0.923)$ & 0.764 & $12(0.841), 7(0.159)$ & 0.990 & irs \\
\hline MEAN & 0.808 & - & 0.911 & - & 0.891 & - \\
\hline
\end{tabular}

* Each bank is a DMU and the peer weights are given within bracket with peers.

The VRS efficiency results also give output scale efficiency scores with VRS efficiency scores. A DMU is considered as scale efficient if its output scale efficiency score is equal to one. Only three banks- SOUTHEAST BANK LIMITED (DMU 12), NATIONAL BANK LIMITED (DMU 19) and AB BANK LIMITED (DMU 22) are scale efficient as their output scale efficiency scores are equal to one. So, in common we get three banks DMU 12, DMU 19 and DMU 22 which are efficient under both CRS and VRS assumption and they are scale efficient too.

Whether the DMU is operating in an area of increasing or decreasing returns to scale can be checked by running an additional DEA problem with non-increasing returns to scale (NIRS) imposed. If the NIRS TE score and VRS TE score are unequal for a DMU, then increasing returns to scale (IRS) exist for that DMU. For our given data, DRS exist for DMU 6, 16, 20 and 23. IRS exists for the remaining 17 DMUs other than 12, 19 and 22 .

The peer weights give the weights to construct a linear combination of the efficient banks to represent an inefficient one. The descriptive statistics of the technical efficiency scores obtained from these methods are given in table 3 .

The mean and median of TE scores of CRS DEA is smaller than other two methods. Maximum TE score is one for all methods but mini- 
mum score is not same for all the three methods. The range (maximum-minimum) is biggest for CRS DEA and smallest for VRS DEA. Standard deviation of TE scores also reflects this. A graphical comparison of CRS TE scores, VRS TE scores and scale TE scores is shown in figure 1.

Table 3: Descriptive Statistics of TE Scores for $n=24$ Banks

\begin{tabular}{|c|c|c|c|c|c|}
\hline Methods & Mean & Median & Maximum & Minimum & Standard Deviation \\
\hline CRS DEA & 0.8076 & 0.8095 & 1.0000 & 0.4750 & 0.1276 \\
\hline VRS DEA & 0.9086 & 0.9970 & 1.0000 & 0.6380 & 0.1223 \\
\hline SCALE & 0.8912 & 0.9155 & 1.0000 & 0.4750 & 0.1170 \\
\hline
\end{tabular}

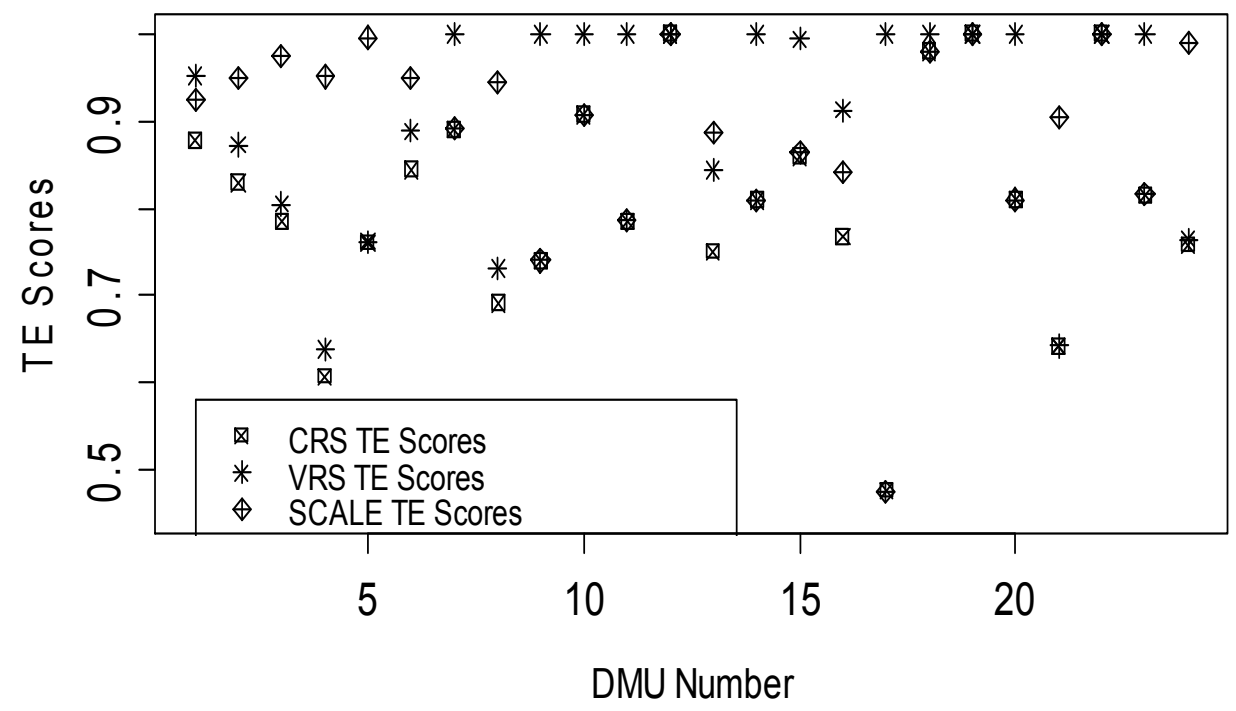

Figure 1 - Comparison Graph of CRS DEA, VRS DEA and Scale TE Scores

\section{CONCLUSION}

Here CRS DEA gives 3 efficient banks (DMUs 12, 19 and 22), VRS DEA gives 12 efficient banks (DMUs 7, 9, 10, 11, 12, 14, 17, 18, 19, 20, 22 and 23). Now we can rank the banks according to their efficiency scores. The banks with higher technical efficiency posses top ranks. Here few banks have efficiency scores equal to one and their ranking can be determined by considering peer counts. However, the most efficient bank is SOUTHEAST BANK LIMITED (DMU 12) which is valid for all methods applied. This is because in CRS DEA efficient DMU 12 has 20 peer counts while other efficient DMU 19 and 22 have only 7 and 6 respectively. DMU 12 possesses rank 1 and DMU 19 and DMU 22 have rank 2 and rank 3 respectively. Other rankings are done according to the decreasing value of the TE scores. Similar ranking can be provided in VRS DEA case. Here efficient DMUs 7, 10, 12, $18,19,20$ and 22 posses ranking 4, 2, 1, 5, 3, 6 and 7 respectively.

The study found that CRS-DEA consists of 3 efficient banks and the range of the efficiency scores is too large whereas VRS-DEA consists of
12 efficient banks and the range of efficiency scores is smaller than CRS-DEA. So, it may be inappropriate to use CRS-DEA instead of VRSDEA in this case. Again, VRS assumption overcomes the shortcoming of CRS assumption which supports the idea of Banker et al. (1984) and seems to be more appropriate.

However, as mentioned by Avkiran (1999), DEA provides insights on which areas need to be improved but it does not have information on how to improve. Further investigations are needed in order to identify approaches for each bank to increase operation profit by moving towards the efficient frontier. 


\section{REFERENCES}

Avkiran, N. K. (1999), The evidence of efficiency gains: The role of mergers and the

benefits to the public, Journal of Banking and Finance 23, 991-1013.

Banker, R. D., Charnes, A. and W. W. Cooper, (1984). Some Models for Estimating Technical and Scale Efficiencies in Data Envelopment Analysis. Management Science 30(9), 1078-1092.

Berger A.N. (2007). International comparisons of banking efficiency. Financial Markets, Institu $\neg$ tions and Instruments, Vol. 16 (3), pp. 119-144.

Bhattacharyya, Arunava, Lovell, C.A.K. and Sahay, Pankaj., (1997). The impact of Liberalization on the productive efficiency of Indian commercial banks. European Journal of Operational Research, Vol. 98, Issue 2, 332-346.

Charnes, A., W.W. Cooper and E. Rhodes, (1978). Measuring the Inefficiency of Decision Making Units. European Journal of Operational Research, 2(6), 429-444.

Coelli, T. (1996). A Guide to FRONTIER Version 4.1: A Computer Program for Stochastic Frontier Production and Cost Function Estimation. CEPA Working Paper No. 96/07, Centre for Efficiency and Productivity Analysis, University of New England, Armidale.

Dwivedi A.K. \& Charyulu D.K., (2011). Efficiency of Indian Banking Industry in the Post Reform Era. Indian Instute of Management, Ahmedabad, India. W.P. No. 2011-03-01.

Farrell, M.J., (1957). The Measurement of Productive Efficiency. Journal of the Royal Statistical Society Series A. General 120(3), 253-282.
Jackson, P. M., and Fethi, M.D., (2000). Evaluating the technical efficiency of Turkish commercial banks: An application of DEA and tobit analysis. International DEA Symposium, University of Queensland, Brisbane, Australia, 2-4.

Siriopoulos, C., Tziogkidis, P. (2009). How do Greek banking institutions react after significant events? - A DEA Approach (forthcoming in Omega).

Subhass, C.Ray \& Abhiman Das (2010): Distribution of Cost and Profit efficiency: Evidence from Indian Banking, European Journal of Operational Research, 201,Pp: 297-307.

Sufian, F. (2010). Modelling Banking Sector Efficiency: A DEA and Time Series Approach. ISSN 1392-1258. Ekonomika 2010 Vol. 89(2).

Sufian, F. (2007). Mergers and acquisitions in the Malaysian banking industry: technical and scale efficiency effects. International Journal Financial Services Management, Vol. 2 (4), pp. 305-326.

Sturm, J.E., Williams, B. (2008). Characteristics determining the efficiency of foreign banks in Australia. Journal of Banking and Finance, Vol. 32 (11), pp. 2346-2360.

Sathye, Milind, (2003). Efficiency of banks in a developing economy: The case of India. European Journal of Operational Research, Vol. 148, Issue 3, 662-672.

Seiford, L.M., and R.M. Thrall, (1990). Recent Developments in DEA: The Mathematical Programming Approach to Frontier Analysis. Journal of Econometrics vol. 46, 7-38. 